\title{
Randomized study comparing the efficacy of a self-retaining bicanaliculus intubation stent with Crawford intubation in patients with canalicular obstruction
}

\author{
This article was published in the following Dove Press journal: \\ Clinical Ophthalmology \\ 19 December 2011 \\ Number of times this article has been viewed
}

\author{
Syed Ziaeddin Tabatabaie \\ Mohammad Taher Rajabi \\ Mohammad Bagher Rajabi \\ Bahram Eshraghi \\ Eye Research Center, Farabi Eye \\ Hospital, Tehran University of Medical \\ Sciences, Tehran, Iran
}

\begin{abstract}
Background: The purpose of this study was to compare the efficacy of self-retaining stent (SRS) bicanalicular intubation with bicanalicular silicone (Crawford) intubation in patients with canalicular and punctal obstruction.

Methods: In this prospective, randomized clinical trial, 38 patients with canalicular or punctal obstruction (25 partial, 13 complete) and epiphora were randomized into two groups. Twenty-one patients (14 with partial and seven with complete obstruction) underwent SRS intubation and 17 patients underwent bicanalicular silicon intubation in a randomized fashion.

Results: After a mean follow-up of 6 months following tube removal, 16 (76\%, 12 partial, four complete) of the 21 eyes in the SRS intubation group and 13 (76\%, 10 partial, three complete) in the bicanalicular silicon intubation group had a successful outcome and remained symptomfree. For partial obstructions, the success rate was $85 \%$ and $90 \%$ for the SRS and bicanalicular silicon intubation groups, respectively. The corresponding values for complete obstruction were $63 \%$ and $50 \%$ for the SRS and bicanalicular silicon intubation groups, respectively.

Conclusion: SRS could effectively substitute for a more extensive procedure such as bicanalicular silicon intubation in patients with canalicular obstruction, particularly those with partial obstruction. The newly developed SRS intubation procedure has the advantages of simple, easy implementation and extubation, low cost, and a lower rate of trauma when compared with bicanalicular silicon intubation.
\end{abstract}

Keywords: self-retaining bicanalicular intubation, Crawford intubation, canalicular obstruction

\section{Introduction}

Punctal or canalicular stenosis is a frequent cause of epiphora resulting from various etiologies, such as chronic blepharitis and conjunctivitis, eyelid malposition, trauma, adverse effects of topical or systemic medications, and neoplasm involving the eyelid. An increased incidence of punctal and canalicular stenosis has been noted in patients receiving systemic chemotherapy, such as docetaxel or 5-fluorouracil. ${ }^{1-3}$ Patients often present with complaints of tearing and epiphora due to insufficient drainage. The condition can be seen in any age group.

The classical management of canalicular stenosis is identification of the causative agent and, if possible, its cessation, but often this is not possible. Patients with symptomatic canalicular stenosis should undergo timely insertion of a bicanalicular silicon stent to prevent permanent and complete closure of the canaliculi. There are several modalities of 
canalicular intubation for patients with canalicular obstruction. In patients with nasolacrimal duct and canalicular obstruction, preferred procedures include dacryocystorhinostomy with bicanalicular intubation or monocanalicular intubation. However, in patients with canalicular obstruction without nasolacrimal duct obstruction, some prefer to use Goldberg cerclage or bicanalicular silicon intubation. Recently, a new design has been developed known as the self-retaining stent (SRS, FCI Ophthalmics, Issy-Les Moulineaux, France) for patients with punctal or canalicular stenosis or obstruction. In this study, we compared the efficacy and safety of SRS intubation with that of bicanalicular silicone (Crawford) intubation in patients with canalicular obstruction.

\section{Materials and methods}

In this prospective comparative interventional case series, 38 eyes from 38 consecutive patients with punctal or canalicular stenosis or obstruction were included. Punctal stenosis was detected on slit-lamp examination and diagnostic probing. Diagnosis of canalicular stenosis or obstruction was made on the basis of a diagnostic probing test. If complete obstruction was detected, patients were only included if they had membranous canalicular obstruction, so that the probe could be forwarded after a click sensation and pass the membrane within the canaliculi. The patients underwent SRS insertion under local anesthesia or bicanalicular silicon intubation under local or general anesthesia from October 2009 to September 2010. Patients were excluded if they had previous eyelid and/or lacrimal surgery, a lump overlying or involving the punctum and/or other parts of the tear drainage system, long complete upper lacrimal system obstruction (canaliculi and common canaliculus) on diagnostic probing, or nasolacrimal duct stenosis or obstruction on irrigation testing. The surgical options were explained, and informed consent was obtained. Patients were allocated a number in order of referral and were then randomly allocated into two groups.

\section{Self-retaining stent}

The SRS consists of a silicon tube $25 \mathrm{~mm}, 30 \mathrm{~mm}$, or $35 \mathrm{~mm}$ long and $0.64 \mathrm{~mm}$ wide, with an anchor-shaped head at each end to allow fixation. Each head consists of two flexible winglets that fold inwards during insertion through the punctum and spread back out after passage through the junction of the common canaliculus and lacrimal sac, thus securing stent fixation (Figure 1). A centrally placed marking on the tube acts as a reference point and allows verification of proper stent positioning following insertion. Insertion is performed in the office under slit-lamp. Both eyes can be intubated at the

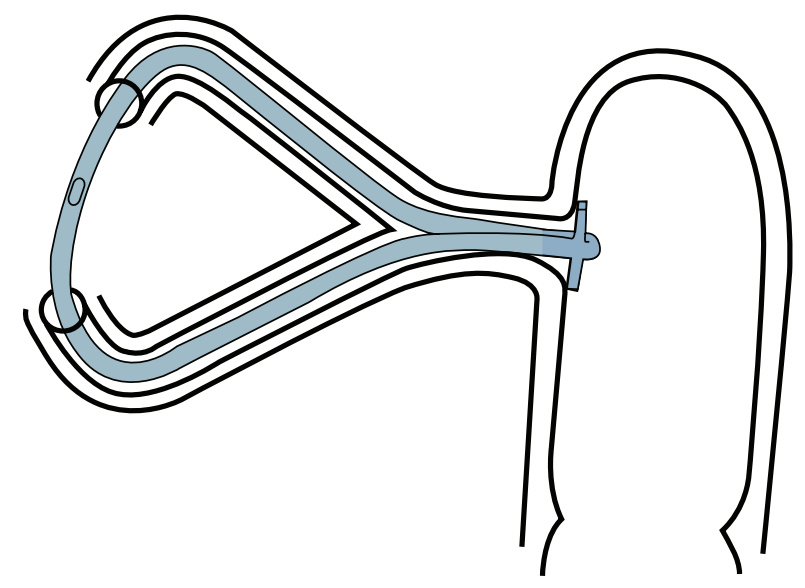

Figure I Illustration showing components of the self-retaining bicanaliculus stent and its fixation in the lacrimal system.

same time if necessary, and the stents remain in position for several weeks. The SRS is indicated for horizontal lacrimal duct obstruction and in particular for punctal stenosis. Other indications include punctal pathologies (ie, senile, postradiotherapy, post-chemotherapy, dermatological stenoses), canalicular pathologies (ie, infectious, traumatic), prevention of canalicular stenoses during radiotherapy and viral infections, and tearing as a result of permeable lacrimal ducts.

\section{Surgical procedure}

SRS intubation was performed under topical anesthesia in the office under slit-lamp. Bicanalicular silicon intubation was performed in the operating room under either monitored anesthesia or general anesthesia. Local anesthetic was administered around the lacrimal sac and intranasally around the inferior concha. Serially enlarging Bowman probes were inserted (ranging from number 00 to number 1 ) in the stenotic canaliculi to enlarge them prior to silicon intubation. Since the canaliculi were stenotic or short membranous and completely obstructed, the Bowman probes were passed through the strictured canaliculi without creation of a false passage. Bicanalicular Crawford tubes were inserted immediately after dilatation and passing of Bowman probes. Antibiotic and steroid eye drops were applied and the patients were instructed to continue them four times daily for one week. Postoperative follow-up examinations were performed at one week, one month, 3 months, and every 3 months thereafter. Tubes were left in place for a minimum of 3 months unless they became extruded.

\section{Outcome measures}

Epiphora was subjectively evaluated based upon patient satisfaction and clinical improvements by our grading scale, 
as follows: good improvement (free of epiphora), moderate improvement (strong improvement with occasional intermittent epiphora), or no improvement. Follow-up was undertaken by an ophthalmologist blinded to the type of probing utilized. At each follow-up visit, epiphora was determined according to the patient's grading scale, and the results were recorded in a database. Final clinical improvement was assessed at the end of follow-up and defined as successful, acceptable, or no improvement. All patients underwent probing with irrigation at their final visit.

\section{Results}

Thirty-eight eyes ( 38 canaliculi) from 38 patients ( 23 female, 15 male) with canalicular obstruction and epiphora were randomized into two groups. Obstruction was partial in 25 patients and complete in 13 . Twenty-one patients (14 partial obstruction, seven complete obstruction) were included in the SRS group and 17 patients (11 partial obstruction and six complete obstruction) in the bicanalicular silicon intubation group (Table 1). The underlying etiologies were unclear in 12 patients, while eight patients had a history of chemotherapy, nine had a history of infection, and nine had a history of an adverse reaction to local medication. The average patient age was $52.4 \pm 7.5(21-68)$ years.

The silicon tubes were left in place for on average $3 \pm 2.6$ (3-6) months. Mean duration of follow-up after tube removal was $6.2 \pm 1.1$ (range 5-8) months. Immediate clinical outcome (at postoperative week 1) was successful in 20 of 21 eyes $(95.2 \%)$ in the SRS group and 15 of 17 eyes $(88.2 \%)$ in the bicanalicular silicon intubation group. Final clinical evaluation was performed at the last visit. The clinical outcome was successful in 16 of 21 eyes in the SRS group (76.2\%). More specifically, five (23.8\%) and 11 (52.3\%) eyes had successful and acceptable outcomes, respectively. The remaining five eyes had no improvement reported, and clinical examination revealed no punctal stenosis in these particular cases (see Table 1 for case details). In the bicanalicular silicon intubation group, the outcome was successful in 13 of 17 eyes $(76.4 \%)$ at the final visit. In this group, the success rate was $90 \%$ and $50 \%$ for partial obstruction and complete obstruction, respectively. Four eyes had no improvement, comprising one eye with partial stenosis and three eyes with complete obstruction. Seven eyes (four in the SRS group and three in the bicanalicular silicon intubation group) had punctal stenosis, all of which were successfully intubated, and all of the patients had a satisfactory outcome (good or moderate improvement), with irrigation showing a patent duct. However, in patients with no improvement (five eyes in the SRS group and four eyes in the bicanalicular silicon intubation group), four eyes in each group showed obstructed canaliculi.

\section{Discussion}

The cause of acquired canalicular obstruction or stenosis is often not known, but is usually caused by an inflammatory condition (such as chronic blepharitis, dacryocystitis, infection [eg, herpes simplex, herpes zoster, infectious mononucleosis], trachoma, Stevens-Johnson syndrome, ocular cicatricial pemphigoid, lichen planus, or an idiopathic mucocutaneous inflammatory disease) ${ }^{1}$, trauma (laceration, chemical or thermal burn, dog bite), intrinsic canalicular tumors (eg, papilloma producing occlusion and secondary inflammation), irradiation for basal cell carcinoma, or as a side effect of medication (eg, echothiophate iodide, idoxuridine, topical cytotoxic drugs, antimetabolites, and chemotherapeutic regimens such as docetaxel and paclitaxel). ${ }^{1-3}$ Punctal or proximal canalicular stenosis has also been reported after spontaneous loss of a collared silicon punctal plug in dry eye patients; however, they usually remain asymptomatic with no further complications. ${ }^{4}$

There are multiple reasons for treatment of punctal and canalicular obstruction. Current recommendations involve identifying and potentially treating the underlying etiology in addition to intubation with a silicon tube to re-establish patency. Balloon canaliculoplasty has also been used to treat canalicular obstruction but, although initial success rates were impressive, long-term follow-up has shown high recurrence rates (with only $23 \%-43 \%$ patency in the long term), indicating the importance of concurrent silicon tube intubation of the lacrimal system. ${ }^{5,6}$ However, in a recent report by Zoumalan et $\mathrm{al}^{7}$, the final clinical outcomes after a mean of 6 months of follow-up were successful or acceptable

Table I Outcome of patients undergoing self-retaining bicanaliculus stent intubation or bicanalicular silicon intubation

\begin{tabular}{llll}
\hline & SRS $(\mathbf{n}=\mathbf{2}$ I) I 4 partial, 7 complete & BSI $(\mathbf{n}=$ I7) I I partial, 6 complete & P value \\
\hline Good & I2 (I0 partial, 2 complete) & 7 (6 partial, I complete $)$ & 0.36 \\
Moderate & 4 (2 partial, 2 complete) & 6 (4 partial, 2 complete $)$ & 0.33 \\
No response & 5 (2 partial, 3 complete) & 4 (I partial, 3 complete $)$ & 0.33 \\
\hline
\end{tabular}

Abbreviations: SRS, self-retaining bicanaliculus stent; BSI, bicanalicular silicon intubation. 
in $76.2 \%$ of patients with canalicular stenosis. However, it should be noted that this study contained patients with stenosis rather than obstruction.

Yang et $\mathrm{al}^{8}$ reported their experience with balloon canaliculoplasty in conjunction with manual trephination and silicon tube intubation in patients with complete canalicular obstruction. They reported clinical improvement in 53.6\% of patients with common canalicular obstruction and in $25.0 \%$ of those with monocanalicular obstruction after 12 months of follow-up. Khoubian et $\mathrm{al}^{9}$ reported on the efficacy of trephination and silicon stent intubation based on the level of obstruction in cases with complete canalicular obstruction. In their report, on average, $49 \%$ of eyes had complete relief of epiphora, $38 \%$ had partial relief, and $13 \%$ had no relief. Eighty percent of eyes with distal lower canalicular obstruction had complete relief and 20\% had partial relief of epiphora. For eyes with distal bicanalicular obstruction, 66\% had complete relief and $33 \%$ had partial relief. Patients with common canalicular obstructions had 59\% complete, $29 \%$ partial, and $12 \%$ no relief. Proximal bicanalicular obstructions were the least successful, with 55\% having partial relief and $45 \%$ having no relief.

In the present study, our success rate (defined as a good and moderate response) for both SRS and bicanalicular silicon intubation was $76 \%$. However, when analysis was performed based on type of obstruction (partial or complete), the success rate for partial obstruction was $85 \%$ and $90 \%$ for SRS and bicanalicular silicon intubation, respectively. For complete obstruction, these values were $63 \%$ and $50 \%$ respectively. Our findings show that both options have good results in cases of partial obstruction, although the success rate is not as high in cases of complete obstruction, but they could be a satisfactory substitute for other surgical procedures, such as dacryocystorhinostomy or Jones tube implantation.

In summary, our study shows that SRS can effectively substitute for a more extensive procedure such as bicanalicular silicon intubation in patients with canalicular obstruction, particularly in those with partial obstruction. The benefits of the newly developed SRS are that it is a simple procedure to perform, with easy implantation and extubation, low cost, and a lower rate of trauma compared with bicanalicular silicon intubation. In cases of complete obstruction, our success rate was not as high as in those with partial obstruction, but it would still be worthwhile to do these procedure even in these cases instead of a more extensive procedure, such as dacryocystorhinostomy accompanied by silicon intubation or Jones tube implantation.

\section{Disclosure}

The authors report no conflicts of interest in this work.

\section{References}

1. Durrani OM, Verity DH, Meligonis G, et al. Bicanalicular obstruction in lichen planus: a characteristic pattern of disease. Ophthalmology. 2008;115:386-389.

2. Esmaeli B, Valero V, Ahmadi MA, et al. Canalicular stenosis secondary to docetaxel (taxotere): a newly recognized side effect. Ophthalmology. 2001;108:994-995.

3. McCartney E, Valluri S, Rushing D, et al. Upper and lower system nasolacrimal duct stenosis secondary to paclitaxel. Ophthal Plast Reconstr Surg. 2007;23:170-171.

4. Boldin I, Klein A, Haller-Schober EM, et al. Long-term follow-up of punctal and proximal canalicular stenoses after silicone punctal plug treatment in dry eye patients. Am J Ophthalmol. 2008;146:968-972.

5. Ko GY, Lee DH, Ahn HS, et al. Balloon catheter dilation in common canalicular obstruction of the lacrimal system: safety and long-term effectiveness. Radiology. 2000;214:781-786.

6. Lee JM, Song HY, Han YM, et al. Balloon dacryocystoplasty: results in the treatment of complete and partial obstructions of the nasolacrimal system. Radiology. 1994;192:503-508.

7. Zoumalan CI, Maher EA, Lelli GJ Jr, Lisman RD. Balloon canaliculoplasty for acquired canalicular stenosis. Ophthal Plast Reconstr Surg. 2010;2:459-461.

8. Yang SW, Park HY, Kikkawa DO. Ballooning canaliculoplasty after lacrimal trephination in monocanalicular and common canalicular obstruction. Jpn J Ophthalmol. 2008;52:444-449.

9. Khoubian JF, Kikkawa DO, Gonnering RS. Trephination and silicone stent intubation for the treatment of canalicular obstruction: effect of the level of obstruction. Ophthal Plast Reconstr Surg. 2006;22:248-252.
Clinical Ophthalmology

\section{Publish your work in this journal}

Clinical Ophthalmology is an international, peer-reviewed journal covering all subspecialties within ophthalmology. Key topics include: Optometry; Visual science; Pharmacology and drug therapy in eye diseases; Basic Sciences; Primary and Secondary eye care; Patient Safety and Quality of Care Improvements. This journal is indexed on Submit your manuscript here: http://www.dovepress.com/clinical-ophthalmology-journal

\section{Dovepress}

PubMed Central and CAS, and is the official journal of The Society of Clinical Ophthalmology (SCO). The manuscript management system is completely online and includes a very quick and fair peer-review system, which is all easy to use. Visit http://www.dovepress.com/ testimonials.php to read real quotes from published authors. 